\title{
Vivendo na Bolívia: uma análise do fluxo de estudantes brasileiros para Santa Cruz de La Sierra
}

\author{
Juliana França Varella*
}

\begin{abstract}
Resumo: 0 presente artigo aborda o trânsito de estudantes brasileiros oriundos da cidade de Nova Xavantina (MT) para Santa Cruz de La Sierra, na Bolívia, com vistas a se graduarem em medicina por universidades particulares bolivianas. Ele resulta de breve inserção em campo, constituída de entrevistas semiestruturadas e observação participante, centrada na descoberta das motivações e projetos que levaram esses estudantes a se deslocarem para a Bolívia, e também de uma discussão acerca da inadequação dos termos existentes nos estudos de fluxos contemporâneos na Antropologia, especificamente da categoria "migração", para descrever e explicar o movimento que pretendo analisar. Irei compará-lo aos movimentos de migração laboral e estudantil encontrados em estudos de fluxos; farei uso da ótica dos "ritos de passagem" e dos conceitos de projetos e campo de possibilidades para demonstrar a sua especificidade; e concluirei com a afirmação da necessidade de se pensar em novos termos em Antropologia para categorizar esse tipo novo de fluxo.
\end{abstract}

Palavras-chave: Bolívia, estudantes brasileiros, projetos, ritos, fluxos contemporâneos.

\section{Introdução}

0 presente artigo visa analisar brevemente o fluxo de estudantes brasileiros para a Bolívia, com vistas a se graduarem no curso de medicina. Para começar a compreender esse movimento, pretendo analisá-lo e descrevê-lo em termos do que a literatura antropológica tem dito sobre os fluxos contemporâneos de pessoas, buscando aproximações e distanciamentos em relação ao trânsito que me proponho analisar, para então discutir a pertinência de certas categorias utilizadas pelos estudos de migração em Antropologia para a compreensão do fluxo em questão, preocupando-me em ressaltar a sua especificidade.

A partir de entrevistas semiestruturadas e observação participante realizadas na cidade de Nova Xavantina com alguns desses estudantes em fluxo, pude reunir alguns dados para iniciar a minha investigação. Além disso, busquei informações a respeito da dimensão desse fluxo. Infelizmente, o contato com a embaixada boliviana em Brasília não foi possível ${ }^{1}$.

\footnotetext{
* Graduada em Ciências Sociais - UNB

${ }^{1}$ Infelizmente, após várias tentativas de contato, não consegui ter acesso aos dados fornecidos pela embaixada da Bolívia no Brasil. Apesar de esses dados não estarem presentes neste trabalho, pretendo explorá-los em minha monografia, para que a dimensão desse fluxo se torne mais clara e para que eu possa começar a pensar sobre o
} 


\section{O movimento: problemas conceituais}

Uma breve pesquisa sobre "estudantes brasileiros na Bolívia" na internet traz inúmeros resultados, que representam a dimensão que esse fluxo vem tomando. Algumas reportagens especulam o número de estudantes brasileiros na Bolívia, que está, segundo algumas delas, em torno de seis mil; outras relatam os problemas que eles sofrem no país por conta de discriminações por parte do governo, instabilidades políticas, dificuldade de validação do diploma e obtenção do CRM no Brasil, entre outros temas ${ }^{2}$.

Segundo as pessoas que entrevistei, "tá todo mundo indo". Pelos relatos que ouvi, há muitas pessoas de Nova Xavantina que estão optando por estudar medicina na Bolívia por conta do preço do curso e do custo de vida, que são bem baixos, especialmente pelo fato da moeda boliviana ser desvalorizada em relação ao real. Outro fator comumente relatado é a ausência do vestibular ou de qualquer outro tipo de prova para que a matrícula seja efetuada, o que facilita a entrada dos alunos nessas universidades.

Ao buscar a bibliografia sobre migração, encontrei apenas algumas categorias que me seriam úteis. Isso porque a finalidade desse tipo de movimento que me proponho analisar é a formação acadêmica e intelectual, em que o estudante tem o apoio financeiro da família para morar fora, sem que precise, por exemplo, trabalhar. Outro fato que a afasta dos estudos de migração laboral é a imagem do país de destino. A Bolívia, ao contrário da Europa ou dos Estados Unidos, lugares comuns de destino de migrantes laborais, é vista com maus olhos por muitos estudantes, que veem o país como atrasado e precário. A Bolívia é, assim, encarada como "última opção", já que cursar medicina no Brasil é inviável financeiramente, bem como passar no vestibular de uma universidade pública, um sonho distante.

impacto deste movimento para os dois países.

\footnotetext{
${ }^{2}$ A TV Globo chegou a exibir uma reportagem especial no Fantástico do dia 05 de junho de 2011 acerca de brasileiros que buscam o curso de medicina no exterior, sobretudo na Bolívia, por conta das mensalidades baratas, mas que acabam por não conseguir exercer a profissão no Brasil. Além disso, a reportagem tratou das dificuldades econômicas pelas quais passam esses estudantes e entrevistou suas famílias, que estavam muito dispostas a mandar para o exterior o pouco e suado dinheiro que conseguiam para manterem seus filhos no curso de medicina. A reportagem pontua ainda a necessidade de se formar mais médicos para trabalhar no Brasil e médicos que estejam adequadamente preparados. Fonte: <http://video.globo.com/Videos/Player/Noticias/0„GIM15289247823-BRASILEIROS+SE+FORMAM+EM+MEDICINA+NO+EXTERIOR+MAS+NAO+CONSEGUEM+TRABALHAR+N $\underline{\text { O+BRASIL,00.html }}$. Acesso em 10 de junho de 2011.
} 
0 que foi encontrado nas bibliografias sobre o movimento de estudantes (Subuhana, 2009; Mungoi, 2006; Morais, 2009; GuSMÃo, 2008; CosTA, 2008), apesar de muito mais próximo da realidade que pretendo analisar, também guarda uma diferença com relação ao meu caso: esses estudos, assim como os de migração laboral, analisam a mobilidade - nesse caso de estudantes - em direção a países considerados mais adiantados e desenvolvidos economicamente do que os seus países de origem e dos quais fazem boa imagem, ao contrário dos estudantes brasileiros que vão para a Bolívia. Há de se considerar, no entanto, que algumas vezes o Brasil não é o destino primeiro desejado pelos estudantes africanos, que prefeririam estudar na Europa, por exemplo, mas que acabam vindo para cá devido a circunstancias às quais estão expostos, a exemplo da existência de projetos de cooperação entre o Brasil e países africanos de língua portuguesa, que facilitam esses fluxos. Esses acordos exigem que os estudantes africanos voltem para os seus países, numa ideia de que, tendo obtido uma boa formação no exterior, podem e devem contribuir para o desenvolvimento nacional. Tal ideologia, entretanto, não foi identificada no caso do fluxo estudantil Brasil-Bolívia, que é, inclusive, desencorajado pelo Itamaraty - segundo entrevista realizada - e fonte de grandes discussões que põem em pauta a dificuldade de avaliar a formação obtida na Bolívia e a forma pela qual integrar esses profissionais no mercado de trabalho brasileiro.

O movimento de estudantes na cidade de Nova Xavantina não é algo recente. Por sediar um dos campi da Universidade do Estado de Mato Grosso, a cidade recebe muitos estudantes e, ao mesmo tempo, manda para outras cidades e estados várias pessoas, que, não satisfeitas com os cursos oferecidos pela UNEMAT em Nova Xavantina, decidem se mudar. Não é novidade, então, que após o término do terceiro ano do ensino médio, os moradores desta cidade decidam cursar a graduação alhures. 0 que chama atenção, no entanto, é esse movimento de estudantes, muitas vezes em grupos, que têm ido para a Bolívia para cursar medicina, que apesar de não ser inédito, parece ter crescido bastante.

Segundo a mãe de uma das estudantes, a escolha pela Bolívia passa ainda pelo fato de lá haver menos burocracia que em outros países da América Latina, como Argentina e Cuba. Já a escolha por Santa Cruz é explicada por sua filha pelo fato de lá já possuírem conhecidos, o que facilitou a organização da viagem, instalação no país, matrícula na universidade e adaptação ao novo país. Apesar da dificuldade conhecida de obter o CRM quando voltam para o Brasil, os pais se mostram confiantes 
e dizem conhecer pessoas que já se formaram na Bolívia, que conseguiram validar o diploma e que estão "bem". Vê-se, portanto, a importância dos retornados e das redes sociais para o incentivo e consolidação do fluxo, fato que será discutido mais adiante.

\section{Antropologia dos fluxos contemporâneos}

Até o final dos anos 50 e início dos anos 60, a Antropologia não dava atenção ao estudo da migração como outras áreas do conhecimento o faziam. E isso pode ser explicado pelo fato de a Antropologia à época entender a cultura como algo restrito a um território, estanque e formada por "unidades homogêneas". Uma vez que os antropólogos reelaboraram essa noção de cultura, tornou-se possível teorizar sobre a migração. Então, percebeu-se um movimento da Antropologia em estudar a migração naquelas áreas que tinham sido, tradicionalmente, os lugares onde os antropólogos faziam seus trabalhos de campo etnográficos, a saber, a África, a Oceania e, cada vez mais, a América Latina e o Caribe. Nesses lugares, os movimentos de pessoas indo do campo às cidades e, mais tarde, a outros países, em números significantes, chamaram a atenção dos antropólogos, cujo interesse pelos migrantes cresceu também com o aumento dos estudos da Antropologia Urbana e dos estudos dos camponeses. O foco da Antropologia na cultura, que inclui o estudo da interação entre crenças e comportamentos, de grupos e de relações sociais, resultou na ênfase que os estudos de migração passaram a dar aos processos de assimilação e mudança cultural, em formas de organização social que caracterizam o processo migratório e a comunidade imigrante, e em questões de identidade e etnicidade (BRETTELL, 2000).

Tentarei reunir neste artigo, portanto, alguns trabalhos que falam sobre o fluxo de pessoas, dos quais retirarei conceitos e ideias para tentar entender o movimento dos estudantes brasileiros para a Bolívia.

Os estudos migratórios trazem questões como a preocupação com os motivos que levam à migração, objetivos que, como têm sido discutido, não são só econômicos, podendo se relacionar a situações de diásporas por motivos religiosos ou - e principalmente - a um projeto familiar que se constitui num "negócio familiar" (HERNAN, 2006), que ao mesmo tempo em que envolve questões econômicas, está muito atrelado a um projeto coletivo viabilizado e impulsionado pela família e por redes sociais bem consolidadas em vários pontos do globo. 0 migrante vai para "fora" para permitir ascensão social de sua família, ele faz um sacrifício em nome do benefício da família, e sofrer faz parte dos discursos comuns. Apesar de esse discurso do sacrifício 
aparecer nas falas dos estudantes brasileiros na Bolívia, aqui a relação se inverte, na medida em que, mesmo se constituindo de um projeto familiar tanto quanto o dos migrantes "laborais", é a família quem se esforça para a manutenção do estudante no exterior e não o contrário. É ela quem o apoia financeiramente e moralmente.

Martes (1999), por exemplo, estuda imigrantes brasileiros nos Estados Unidos. Ela faz um apanhado interessante sobre os variados tipos de explicação que são dados para os fenômenos migratórios. A primeira explicação e talvez a mais conhecida é a da teoria econômica neoclássica, a push and pull theory, ou teoria da atração e repulsão, que enfatiza as desigualdades econômicas que existem entre os países, o que geraria grandes diferenças de incentivos salariais, criando regiões de repulsão e de atração, gerando certo desequilíbrio entre demanda e oferta. No nível macro, a migração por essa teoria é explicada pelas desigualdades socioeconômicas entre as nações e, no micro, por opções individuais. 0 problema desta teoria é que ela ignora fatores de ordem social e cultural (MARTES, 1999, p. 35), como, por exemplo, a importância das redes sociais para originar e sustentar o fluxo migratório, o que ficou claro durante essa pesquisa.

Outra abordagem é uma abordagem mais sociológica que inclui, a título de ilustração, os contextos sociais do país de destino e a influência cultural desses países, como a grande influência que o estilo de vida americano tem sobre o resto do mundo, o que pode ser visto como um importante fator de atração para a migração.

Vale ressaltar que, em meu caso de estudo, considerações econômicas relativas ao mercado de trabalho e à produção não explicam o movimento, cuja finalidade é a graduação em medicina. Os estudantes não pretendem trabalhar na Bolívia, todos afirmaram o desejo de voltar para o Brasil e de aqui exercerem a profissão. Outro fator instigante é que a Bolívia não os atrai do ponto de vista do estilo de vida ou culturalmente e, pelo contrário, quase todos demonstram ressalvas ao país. Como a mãe de uma entrevistada falou: "todos os brasileiros, eles ficam lá [na Bolívia], mas é por necessidade mesmo, sabe?".

Diferente da abordagem neoclássica, a sociológica leva em conta o papel das redes sociais. Segundo Martes (1999, p. 44): “ao homem econômico se contrapõe o homem solidário ${ }^{3}$ e, ao indivíduo, as redes sociais a que ele pertence”. A abordagem sociológica parece-me especialmente proveitosa para este trabalho, principalmente

\footnotetext{
${ }^{3}$ Martes questiona esse pressuposto da solidariedade entre os conterrâneos, uma vez que tomá-la como um dado, e não algo a ser investigado, pode acabar por ignorar possíveis relações de poder, conflito e competição.
} 
no que diz respeito à centralidade que dá ao papel desempenhado pelas redes sociais, de amizade, de conhecimento ou de relações de parentesco.

Vários autores parecem fazer uso dessa concepção. Segundo diversos estudos, a facilidade de organização para a viagem, bem como para a adaptação do migrante no local de destino, depende de uma rede social consolidada e, no caso da migração laboral, de uma rede social constituída em sua maioria por parentes. A presença de parentes que deem suporte aos novos migrantes no país de destino configura-se como fator que diminui os custos financeiros e emocionais do processo migratório (HERNAN, 2006; FAZITO, 2010; FlEISCHER, 2002; MARTES, 1999). 0 critério de aproximação comumente retratado pelos autores para a constituição de redes sociais no local de destino é o da origem nacional e/ou étnica comum (Mungoi, 2006; SubuhanA, 2009).

Nas falas de estudantes entrevistadas, é possível perceber a relevância da constituição dessas redes, de conhecer pessoas no local de origem e de casos de "sucesso" para o incentivo ao fluxo:

[...] já, já conhecia [alguém que tinha ido pra Bolívia estudar e depois voltado para o Brasil], o Doutor M., assim não conhecia, eu tinha uma ligação só com ele, ele foi, se formou lá, e pelo que eu sei, não sei assim direito, ele fez uma prova aqui e passou nessa prova pra conseguir o CRM, só isso que eu sabia dele. Aí falei 'ah, então dá certo, então eu vou arriscar né' [...].

[...] Aí, o J., da minha sala, sempre quis medicina, aí começou a conversar comigo, eu quero na área da saúde e ele falou "ah, vamo fazer medicina lá" e eu falei assim "ah, não sei". Aí a irmã do L. (a entrevistada que chamo de A.) tava aqui, a A., aí eu fui conversar com ela [...] e toda vez que a gente ia lá conversar com ela, ele vinha aqui me buscar e me enchia o saco dizendo "vamo, vamo", aí eu comecei a gostar da ideia, falei 'ah, tá', aí conversei com meus pais e eles falaram "ah, M., você pode tentar, se não der certo, você volta", aí falei "ah tudo bem", aí eu fui e vi que dava certo. [...] já tinham me falado que o ensino era bom, o ensino realmente é muito bom, e também por meu amigo ter ido né ajudou também, porque eu não iria sozinha logo de cara [...].

A migração é comumente vista como um projeto não apenas individual, mas sobretudo familiar, na medida em que é a família a entidade que possibilita a ida do migrante. Ela fornece o suporte financeiro e emocional para que este possa se deslocar e se manter no exterior. Os estudos sobre migração laboral têm por foco também a questão da desorganização familiar, ou como outros autores preferem, a reorganização da família em contextos transnacionais (MACHADO, 2010). Esses autores ressaltam a troca de papéis que existe no contexto migratório quando, por exemplo, avós viram "mães" de seus netos, às vezes até mesmo de forma permanente (isto é, mesmo após o retorno da mãe emigrada, a criança permanece morando com a avó). Os membros se esforçam para criar sentimentos de pertencimento e de unidade da família transnacional. 
Entretanto, não é só no local de origem que a questão familiar é abordada. Alguns autores falam de criação de parentesco social (relatedness) no local de destino, num contexto em que casa é confundida com família. Esse parentesco social se cria pelo convívio efetivo (FonsECA, 2002).

Outro ponto de relevância considerável é o fluxo de bens e dinheiro entre origem e destino como forma de manter laços sociais e "cumprir promessas" (LoBo, 2010). Os emigrados, apesar de distantes, se fazem presentes na vida dos familiares que ficaram no local de origem, continuando a participar, por exemplo, de decisões familiares. Pode haver tensão entre desestruturação da família e planos e projetos familiares. Há uma preocupação em verificar se há efetivamente manutenção de afetividade à distância e, nesse sentido, saber se há envio de remessas de dinheiro, troca de presentes e compartilhamento de informações e de que forma isso pode contribuir para essa investigação acerca da manutenção de laços de afetividade. 0 contato entre família e emigrado é também ponto de convergência em muitos estudos, principalmente, no que diz respeito às tecnologias do contato. 0 uso frequente do telefone e da internet contribui para o encolhimento das distâncias e, logo, para a maneira como as relações são mantidas entre eles. Vale dizer que se de um lado essas tecnologias são importantes por manterem o vínculo afetivo, por outro, elas têm o lado negativo de propiciar condições para que o que está fora seja mais cobrado pela família, o que faz com que alguns migrantes se sintam oprimidos e impotentes frente às demandas familiares (SARGENT; LARCHANCE-KIM; YATERA, 2007). Importante ressaltar que na maior parte dos trabalhos a que tive acesso, a distância aparecia como um problema maior para as relações familiares no caso da migração laboral.

A partir de minha pesquisa, pude ver que os contatos diários efetuados entre os estudantes brasileiros na Bolívia e suas famílias no Brasil são suficientes para a manutenção de uma afetividade e que o tema da desestruturação familiar não faz para eles muito sentido. Segundo as estudantes com quem conversei, os contatos que fazem com a família são frequentes, seja por telefone ou internet, os meios mais utilizados, e não há, segundo elas, nenhum tipo de desestruturação familiar devido à distância, talvez pelo fato de o papel exercido pelo emigrado ser bem diferente do papel exercido pelo estudante migrante. Essa inversão de papéis passa também pelo fato de, ao contrário do que ocorre nos casos de migração laboral, não serem os estudantes os responsáveis pela geração de renda no exterior e posterior envio desse dinheiro para o sustento da casa no país de origem. Fica patente a discrepância do 
projeto que define a migração - laboral - e aquele que impulsiona a ida do estudante para o exterior.

De um lado, estudos sobre fenômenos de migração laboral e, de outro, estudos a respeito do fluxo de estudantes, em especial, estudantes africanos. Os dois tipos de trabalho me foram úteis. No entanto, os estudos sobre o fluxo de estudantes me revelaram algumas categorias próprias do estudo de mobilidade com fins de estudo, o que eu creio ser mais coerente com o tipo de fenômeno que pesquiso. A multiplicidade de termos que encontrei para definir esse tipo de movimento me chamou a atenção: "deslocamento com a finalidade de estudo"; "migração temporária", "migrante temporário", "migrante sazonal", entre outros. Essa emergência de vários termos vem reforçar minha suspeita de que se trata sim de um tipo movimento bem diferente daquele dos estudos de migração.

Ao contrário do que aparece em estudos acerca de migrantes que buscam trabalho no exterior (MARTES, 1999), a competição entre os estudantes em fluxo não aparece como fator desagregador, uma vez que eles não estão competindo no mercado de trabalho. No geral, há um nível elevado de solidariedade entre esses estudantes, especialmente entre aqueles que compartilham mesma origem nacional e étnica. Entre os estudantes, o fenômeno de ajuda mútua está muito presente, há uma relação de camaradagem entre os conterrâneos, mesmo que desconhecidos.

Os trabalhos acerca dos estudantes africanos a que tive acesso discutem questões raciais e étnicas, bem como identitárias. A discriminação sofrida por eles nos locais de destino é ponto de convergência entre vários autores. Além disso, cisões internas ao grupo dos "estudantes africanos" ficam latentes nesses estudos, uma vez que existem inúmeras diferenças intragrupos que podem não ficar aparentes quando se olha para o grupo sob o rótulo de "africano". Essas cisões também se relacionam com todo um jogo de identidades - contrastivas - que é marcado pelo acionamento de diferentes traços identitários de acordo com as situações, algo que também ocorre em outros contextos migratórios quando, por exemplo, atores sociais tentam se tornar sujeitos políticos e buscar seus direitos. Dessa forma, um estudante pode ser africano ao se relacionar com brasileiros, e cabo-verdiano ao se relacionar com africanos de outras origens nacionais. Fala-se também em mudança da auto-representação dos migrantes, em crises pessoais, de inserção, problemas identitários, "identidades em trânsito" (CosTA, 2008; MoRAIS, 2009; MungoI, 2006; SUBUHANA, 2009). 
Uma noção importante cunhada por autores que falam de migração laboral é a ideia de que os retornados que conseguem - e devem! - demonstrar, através de diversos símbolos, seu sucesso (tanto em termos econômicos quanto de status) funcionam como estímulo fundamental para novas migrações e, nesse sentido, ajudam a construir um verdadeiro fluxo migratório em direção à determinada região. Os "casos de sucesso" funcionam não só para influenciar outras pessoas a migrarem, mas os sujeitos considerados triunfantes podem, inclusive, acabarem por se tornar agenciadores "profissionais" de viagem, facilitando a ida de mais migrantes (FAzITo, 2010). O retorno é algo desejado, pois é o momento em que se conclui o ciclo, em que se mostra aos demais o prestígio adquirido. Essa ideia se insere no contexto dos estudantes brasileiros na medida em que eles retornam para a sociedade de origem com o diploma de médico, o que lhes confere um status diferenciado em relação às pessoas de sua sociedade e em relação a uma condição anterior que eles mesmos possuíam. A partir dessa noção, considero interessante a utilização do conceito de "rito de passagem", com suas três fases principais, para especificar o fluxo tratado.

Num primeiro momento, eles se afastam de um tipo de vida ao qual estavam acostumados: deixam suas casas, terra natal, parentes e amigos, saindo também da condição de estudante de ensino médio ou pré-vestibular, para a condição de estudante de medicina na Bolívia, estrangeiro e pessoa que mora "sozinha". Esta série de rupturas é acompanhada e marcada pela distância espacial entre os dois lugares.

Em seguida, esses estudantes, já distantes de uma condição anterior de vida, viveriam numa espécie de fase de transição e liminaridade, período de separação da família (isolamento), em que há a suspensão da estrutura social, os alunos se encontram em um contexto diferente daquele em que se encontravam antes e diferente também daquele que encontrarão posteriormente, na fase de reagregação, quando serão médicos, e se agregarão novamente à família e à sociedade de origem, com outra posição social, superior.

É possível pensar também na ideia que Turner (1974) desenvolve acerca dos discursos de sofrimento que permeiam a fase de liminaridade. 0 discurso de "sofrer faz parte" pode ser encontrado tanto nos estudos acerca dos estudantes africanos no Brasil quanto nas falas dos estudantes brasileiros que estão na Bolívia. Essas falas, que se apegam à ideia de que problemas e dores que enfrentam fora do país de origem "fazem parte", deixam explícitas algumas das características que Turner associa à fase da liminaridade num rito de passagem: visão conformista, comportamento 
passivo e humilde, bem como o conformismo com a suspensão de alguns prazeres, aceitação de dores e sofrimentos, humilhações. Tudo isso faz parte da destruição de uma condição anterior para que os "neófitos" se remodelem e possam atingir a fase posterior. Outra característica dessa fase de transição é a camaradagem entre aqueles que nela se encontram, como pode ser visto no caso de pessoas que nem se conhecem se ajudarem mutuamente nesse contexto migratório/de fluxo. Esse fato nos leva a pensar no critério de etnicidade e nacionalidade que perpassa as formações das redes sociais dos migrantes no local de destino.

Tentando fazer o paralelo com a ideia das três fases do rito de passagem, de Van Gennep (2011) e Turner (1974), pode-se associar a chamada fase de reagregação com o momento em que esses estudantes voltam para o Brasil, fazem a prova para obtenção do CRM e se tornam, de fato, médicos (o que pode ainda demandar algum tempo de experiência em grandes centros, como São Paulo, antes de exercerem a profissão na cidade de origem). Nesse ponto, fica visível a característica desse movimento como rito de passagem, uma vez que ele que permite a mudança de posição, de status desses estudantes na sociedade de origem e frente às suas famílias.

Apesar da solidariedade encontrada entre os migrantes (especialmente na fase descrita como de liminaridade), alguns autores ressaltam que existem diferentes tipos de migrantes, a exemplo da diferença de escolaridade entre migrantes brasileiros nos EUA ou de origem regional, o que pode gerar clivagens internas ao grupo brasileiro (FLEISCHER, 2002; MARTES, 1999), o que também é válido para o caso dos estudantes africanos: uns vêm com auxílio de bolsa ou do governo; outros, advindos de classes sociais mais elevadas no país de origem, conseguem custear eles mesmos a viagem e permanência no local de destino. Em alguns casos existe o auxílio de ONGs ou instituições religiosas. Essas clivagens são vistas também no caso dos estudantes brasileiros na Bolívia. Segundo uma entrevistada, a questão financeira difere uns estudantes de outros e interfere no tipo de adaptação ao país:

\footnotetext{
Porque tem muita gente que tá lá que não gosta de lá, entendeu? Odeia lá, mas depende também, Juliana, eu entendo porque certas pessoas odeiam, pela condição financeira. Tem gente que tá lá com muito pouca condição financeira, com pouco dinheiro demais. Eu entendo, sabe? Passa dificuldade, o dinheiro lá é pra pagar faculdade, pra morar e pra andar de micro. E o micro lá é uma coisa tão precária, entendeu? É como se fosse uma vanzinha assim, sabe? Que você paga um peso e você tem que ir apertado ali com todo mundo, sorte quando você pega o micro... Tem gente que vai de táxi pra faculdade, tem gente que tem carro, entendeu? Tudo depende da condição financeira. Lá não tem só aluno que, por exemplo, não pode pagar a faculdade, tem muita gente rica lá, mas por quê? Porque não passou no vestibular no Brasil [...].
} 
Tema central tanto nas obras de autores que pesquisam migrações laborais quanto daqueles que falam de estudantes em fluxo é a preocupação com os espaços de sociabilidade entre os migrantes, vistos como vitais para a manutenção dos laços entre eles e entre a sua cultura de origem. Esses espaços podem ser locais de encontro, como igrejas, ou mesmo festas, organizadas por eles mesmos. São locais de identificação entre os migrantes. Para os estudantes brasileiros, a igreja e a universidade são espaços importantes para a sociabilidade e as festas de aniversários (em sua maioria de conterrâneos), momentos propícios para o encontro de iguais e trocas de afetividade.

Um aspecto que tem sido discutido em muitos casos, seja de migração laboral ou não, é a ideia da mobilidade como um valor positivo. Se deslocar é algo bem visto em certas sociedades e o fluxo pode até mesmo fazer parte de sua estrutura social. No entanto, há de se considerar para onde se vai e de que forma.

Algumas pesquisas trazem, por vezes, como abordagem, o elemento da memória, principalmente, quando a intenção é resgatar elementos da cultura de origem e fazer a comparação do "lá" e do "cá". As imagens que se tinha do local antes de conhecê-lo são também explorados. A esse respeito, muitos estudos falam da mídia como importante veículo de informações e de criação de imagens acerca de uma localidade de destino (Subuhana, 2009). Como uma estudante me relatou, a mídia havia lhe transmitido uma imagem negativa da Bolívia que foi, em alguns aspectos, apagada por sua experiência pessoal naquele país:

[...] todas as outras cidades são os "colla", de descendência indígena, que usa aquelas saias, entendeu? Sempre quando você vê uma notícia no jornal, vai mostrar aquilo ali, porque o presidente é "colla" [...].

[...] então quando você vai de carro você vai passar por cidades muito pobres, você vai ver muita coisa feia [...] só que chegando na cidade e Santa Cruz é uma cidade muito grande, gostei muito da cidade, falei "nossa, uma cidade bacana, grande e tem muita coisa, nossa, que legal!". Só que eu tinha uma imagem diferente de uma cidade mais rústica, mais feia e uma coisa mais tipo um povoado assim, só que não, é uma cidade moderna, é uma cidade que em questão de cultura e tudo ela tá uns 20 anos atrás, assim em questão de estrutura, eu falo a estrutura de cidade, ela tá há uns vinte anos atrás. É um estilo Goiânia, mas mais velha, só que em questão tecnológica ela tá avançada uns dez anos a mais que o Brasil, entendeu?

Por fim, as questões da adaptação do migrante ao local de destino são amplamente discutidas, o que envolve, por exemplo, o domínio da língua, fator que pode ser determinante para uma plena adaptação do migrante (FLEISCHER, 2002). Como me contou uma estudante: 
[...] a língua lá é muito diferente, às vezes você não tem noção do que tão falando com você, é muito difícil. Juliana, é o seguinte: lá em Santa Cruz, na Bolívia, tem muito brasileiro, muito brasileiro mesmo, então é assim, pra você aprender a língua você tem que se misturar com eles, você tem que fazer amizade com eles. [...] As meninas, foram umas meninas, e elas ficam muito entre elas, não se misturam com os bolivianos [...].

Os motivos pelos quais as pessoas decidem emigrar são procurados por vários autores que se valem de diferentes perspectivas. Também são amplamente discutidos os motivos que as fazem retornar. Como dito acima, entende-se a necessidade de voltar para fechar o ciclo e atestar um aumento de status e uma "melhora de vida". É na volta que o migrante tem a oportunidade de mostrar o que conseguiu no tempo que esteve fora, e os símbolos do sucesso variam, podendo ser uma casa de três andares, um casamento pomposo ou vestimentas diferenciadas. E quando se fala de estudantes, por que a volta pode ser considerada tão importante? A análise feita acima sob a ótica dos ritos pode nos proporcionar algumas pistas. Além dela, considero essencial dissertar brevemente sobre a noção de campo de possibilidades e projetos, uma vez que acredito que o que diferencia o fluxo de estudantes daquele de "migrantes" é justamente o projeto que está por trás desse movimento. E o projeto é, como será visto adiante, o que dá sentido às ações e guia a vida dessas pessoas, logo, o que pode explicar a importância da volta: ela concretiza e finaliza o projeto buscado.

A concepção de projeto e campo de possibilidades, cunhada por Gilberto Velho (1994) já foi usada para pensar o caso dos estudantes africanos no Brasil (MunGoI, 2006). Velho fala de projeto enquanto uma dimensão mais racional e consciente da ação, como uma conduta organizada para atingir finalidades específicas; e do campo de possibilidades enquanto a dimensão sociocultural, constitutiva de modelos, paradigmas e mapas, espaço para a formulação e implementação de projetos. A dialética entre essas duas dimensões constitui os indivíduos através de suas trajetórias existenciais. Velho fala em associar as noções de projetos e campo de possibilidades para evitar ou um individualismo exacerbado ou um determinismo sociocultural. Esses dois conceitos, juntos, ajudam na análise de trajetórias e biografias enquanto expressão de um quadro sócio-histórico, sem esvaziá-las arbitrariamente de suas peculiaridades e singularidades. Nesse sentido, pode-se pensar nas trajetórias particulares desses estudantes que estão na Bolívia sem perder de vista que eles estão buscando um projeto comum de formação acadêmica, que passa pela ida para Santa Cruz de La Sierra e se encerra na volta, momento em que concluirão esse projeto, que me pareceu central na vida de muitos deles e mesmo de suas famílias, grandes entusiastas desse plano. 
Como exemplo etnográfico, Velho fala do projeto da família de Catarina, uma jovem imigrante nos EUA. Sua família visava melhorar suas condições de vida, por isso, migrou para os EUA. Esse era um projeto coletivo, da família; no entanto, ele era vivido de formas diferentes pelos pais da jovem e por ela mesma. 0 que o autor pretende com esse exemplo etnográfico é dizer que, embora possam existir projetos coletivos e, especialmente no caso de contextos migratórios, eles são muito comuns, eles são vividos de formas diferentes, de acordo com gênero, geração, status, trajetória, origem regional. No caso de Catarina, a variável geracional pode vir a trazer descontinuidade do projeto familiar, na medida em que a jovem vive o projeto de forma diferente dos seus pais e cria para si um projeto seu, individual, que pode entrar em conflito com o projeto da família (ou não).

No caso dos estudantes brasileiros na Bolívia, uma breve inserção em campo me mostrou casos de desentendimentos e formas de compreensão diversificadas sobre o que se deve esperar da "ida para a Bolívia", o que se relaciona com os conceitos cunhados por Velho. Algumas vezes, eram as diferentes atitudes de estudantes frente a esse fluxo que se mostravam conflitantes, segundo um entrevistado: "algumas pessoas são sérias, outras só querem 'festar'”. Outras vezes, conflitos entre pais e estudantes é que eram o problema, justamente pelo fato de estarem os pais com algumas expectativas que podem não ter sido satisfeitas pelos estudantes, que vivenciam esse projeto de ir para a Bolívia de uma forma bem diferente.

Interessante notar que, no caso das migrações laborais, aquele que vai afirma fazer sacrifícios pela família, ele normalmente poupa grande parte do que ganha no exterior para mandar para a família no local de origem, para que eles tenham melhoria na qualidade de vida. Esse caso exemplifica a ideia de projeto migratório como projeto familiar. No caso dos estudantes, pode-se pensar até que ponto o aumento do status e qualidade de vida do estudante proporcionado pelo curso de medicina se estende à família e pode explicar o investimento dos familiares nesse projeto.

A viabilidade dos projetos vai depender, diz Velho, do jogo e interação com outros projetos individuais ou coletivos, da natureza e da dinâmica do campo de possibilidades (VELHO, 1994, p. 47). Vale ressaltar que, assim como as pessoas, os projetos mudam e também as pessoas mudam através de seus projetos, ao longo do tempo e de acordo com os contextos. 0 que pode exemplificar o caso de estudantes que desistem do curso de medicina, apesar de todo o incentivo da família e mesmo possuindo uma rede social bem consolidada na Bolívia. 
0 autor diz ainda que a consistência do projeto depende da memória, que fornece a consciência do passado e das circunstâncias do presente, o que permite a elaboração de projetos (VELHo, 1994, p. 101). O projeto e a memória se associam e articulam ao dar significado à vida e às ações dos indivíduos, ou seja, à própria identidade. Memória (retrospectiva) e projeto (perspectiva) ordenam e dão significado às trajetórias de vida das pessoas (Velho, 1994, p. 102).

O projeto é o instrumento básico de negociação da realidade com outros atores, indivíduos ou coletivos, ele é meio de comunicação; maneira de expressar e articular interesses, objetivos, sentimentos, aspirações para o mundo; ele resulta de uma deliberação consciente a partir do campo de possibilidades (circunstâncias) em que está inserido o sujeito, o que implica reconhecer limitações e constrangimentos (VELHo, 1994, p. 103). 0 indivíduo pode ter mais de um projeto, mas em geral existe um projeto que é central (ex.: virar médico).

Nesse sentido, pode-se especular em que medida estudar medicina é um projeto individual e familiar - vivenciado de forma diferente pelo estudante que vive na Bolívia e pela sua família que fica no Brasil - que está inserido num determinado campo de possibilidades que inclui ir para a Bolívia e lá cursar a graduação, e como esse projeto de se tornar médico se articula com o projeto "migratório" de ir para a Bolívia.

Na sociedade moderna em que vivemos, diz Velho, há uma multiplicidade de motivações e fragmentação sociocultural que produzem necessidade de projetos e trazem ao mesmo tempo a possibilidade de contradição e conflito. Por isso, o projeto é dinâmico e é permanentemente reelaborado, reorganizando a memória do ator, dando novos sentidos e significados, provocando com isso repercussões na sua identidade (Velho, 1994, p. 104). Para exemplificar esse fato, pode-se analisar o caso de estudantes brasileiros que depois de certo tempo desistem do curso, a contragosto de pais, e retornam para o país de origem. Isso com certeza traz conflitos para a família e pode mudar a forma do estudante de se auto-representar enquanto sujeito, dentro e fora da esfera familiar, alterando, assim, sua identidade.

\section{Conclusão}

Pude concluir que se por um lado a literatura de migração ajuda a pensar meu movimento por trazer questões pertinentes ao fluxo de pessoas (motivações e incentivo para o fluxo, criação de redes sociais, questões familiares, adaptação no país de destino, etc.), por outro, ela, diferente da breve literatura sobre estudantes em 
fluxo, não desperta questões referentes à motivação do estudo, de possíveis cooperações internacionais ou mesmo do impacto que novos profissionais formados fora de seus países podem trazer para suas terras natais, a exemplo da ampla discussão acerca da validação do diploma de médicos formados no exterior, que vem também a questionar os meios de avaliação da qualidade dos profissionais formados no Brasil. Outra diferença é que dentro do tema do fluxo de estudantes não cabe abordar, como o fazem os estudos de migrantes laborais, a esfera do trabalho, da competição e da ilegalidade no exterior.

Por se tratar de um tipo diferente de movimento - o fluxo de estudantes brasileiros para a Bolívia - o termo "migração" parece não contemplar a especificidade desse fenômeno, assim como o termo "migrantes" também não aparece nos discursos desses estudantes em trânsito. Tal fato me leva a crer que há a necessidade de se buscar novas terminologias e uma nova categoria para inserir esse tipo de fenômeno que parece, por isso mesmo, distinto daqueles tão discutidos pela literatura antropológica.

0 caso dos estudantes brasileiros na Bolívia se mostrou curioso por dois motivos principais: primeiro, por ser um fluxo de estudantes que visam tão somente o estudo e não competem por emprego no mercado de trabalho boliviano, ao contrário do que ocorre na maior parte dos trabalhos acerca de migrações, que têm como finalidade a análise de fluxos de trabalhadores; e, segundo, porque nos raros e escassos casos em que os estudos migratórios lidam com o fluxo de estudantes e não de trabalhadores, esse fluxo se dá no sentido sul-norte ${ }^{4}$ ou em direção a países que essas pessoas consideram mais desenvolvidos do que os seus países de origem (como no caso do movimento estudantil África-Brasil ${ }^{5}$ ), ao contrário do que se vê no caso do fluxo Brasil-Bolívia (contra fluxo?).

O fato em si de se mudar para a Europa ou mesmo para o Brasil já é visto como algo positivo, ao contrário do que ocorre com os brasileiros na Bolívia. Esse país é visto por eles como última opção, uma vez que seu próprio país não lhe possibilitou cursar a graduação desejada. Os estudantes brasileiros na Bolívia costumam ser, in-

\footnotetext{
${ }^{4}$ Entendo sul-norte não apenas como referenciais de hemisfério sul e hemisfério norte, mas dentro de um contexto em que se compreendem as diferenças de "desenvolvimento" entre as nações. Neste caso, não me refiro apenas ao sul como "hemisfério sul" do globo, mas entendo sul dentro de um contexto de "subdesenvolvimento", se comparado com a visão que se tem dos países "do norte", nações tidas como mais "desenvolvidas" e que, por isso, também abrigariam instituições de ensino mais renomadas internacionalmente.
}

\footnotetext{
${ }^{5}$ Mesmo o Brasil sendo visto pelos estudantes como uma nação de desenvolvimento intermediário, diferente de
} países europeus ou norte-americanos, ele é tido como mais desenvolvido do que os seus países de origem. 
clusive, menosprezados a princípio pela decisão de "migrar". Sair neste caso não é visto como algo positivo, mas pode até mesmo ser considerado atestado de incompetência: "ele não passou no vestibular" ou "os pais dele não podem pagar uma faculdade particular". Enquanto que para os estudantes africanos, o movimento é extremamente positivo, pois ter a oportunidade de estudar fora e em países considerados "mais avançados" que os seus países de origem "não é para qualquer um". Há de se ter condições econômicas para isso ou passar em seleção competitiva para a obtenção de bolsas de estudos.

Dessa forma, é preciso questionar, então, por que esses estudantes brasileiros continuam indo para a Bolívia. Como tentei demonstrar, o estudo de ritos e dos projetos pode auxiliar na compreensão desse questionamento. 0 fenômeno em questão pode ser visto pela ótica do rito de passagem, na medida em que proporciona uma transição, uma mudança de status do estudante quando este volta para a sua sociedade de origem, status esse que parece ser ampliado e abarcar a sua família, quem possibilitou e incentivou a sua ida à Bolívia. Pode-se entender, então, que esse movimento não é um projeto individual do estudante brasileiro, mas está inserido num contexto coletivo, em que ir para a Bolívia foi, dentro do campo de possibilidades em que essas pessoas se inserem, o projeto traçado pela família para alcançar o objetivo profissional de seu (sua) filho (a), que, apesar de ser coletivo, é vivenciado de formas completamente diferentes pelo filho que está na Bolívia e pela família que fica no Brasil.

Como já argumentado, os estudos de antropologia dos fluxos contemporâneos aqui discutidos iluminam a análise do meu caso, mas não são suficientes, dadas as especificidades já comentadas do fenômeno. Assim, acredito ser essencial para a Antropologia repensar essas terminologias e categorias, a fim de criar (quem sabe) algo novo que possa melhor expressar e descrever esse movimento tão singular, que nesse artigo tentei pensar especialmente a partir dos conceitos de ritual e projeto $e$ campo de possibilidades.

\section{Referências}

BRETELL, C. (2000). "Theorizing migration in anthropology: the social construction of networks, identities, communities and globalscapes." In: BRETTELL, C.; HOLLIFIELD, J. F. Migration theory: talking across disciplines. New York: Routledge.

Costa, A. (2008). "Estudantes moçambicanos em Lisboa: dinâmicas identitárias e processos de mudança social e cultural”. Anais 26믈 Reunião Brasileira de Antropologia, Porto Seguro. 
FAZITo, D. (2010). "Análise de redes sociais e migração: dois aspectos fundamentais do 'retorno'”. Revista Brasileira de Ciências. Sociais, São Paulo, vol. 25, n. 72, p. 89-176. Disponível em: <http://www.scielo.br/scielo.php?script=sci_arttext\&pid=S010269092010000100007\&lng=en\&nrm=iso>. Acesso em Set. 2010.

Fleischer, S. (2002). Passando a América a limpo: o trabalho de housecleaners brasileiras em Boston, Massachussets. São Paulo: Annablume.

FonsecA, C. (2002). "Mãe é uma só? Reflexões entorno de alguns casos brasileiros". Psicologia USP, São Paulo, vol. 13 n. 2. Disponível em: <http://www.scielo.br/scielo. php?script=sci arttext\&pid=S0103-65642002000200005\&lng=en\&nrm=iso $>$. Acesso em 20 Out. 2010.

Gennep, A. V. (2011). Os ritos de passagem. Tradução de Mariano Ferreira. 2a ed. Petrópolis: Vozes.

Gusmão, N. M. M. (2008). "Diáspora africana: a vida de imigrantes e estudantes em Portugal e no Brasil”. Anais 26aㅡ Reunião Brasileira de Antropologia, Porto Seguro.

HERMAN, E. (2006). "Migration as a family business: the role of personal networks in the mobility phase of migration". International Migration Review, 44(4), p. 191-230.

Lово, A. S. (2010). "Mantendo relações à distância: o papel do fluxo de objetos e informações na configuração de relações familiares transnacionais em Cabo Verde". In: TRAJANO FILHO, W. (Org.). Lugares, pessoas e grupos: as lógicas do pertencimento em perspectiva internacional. Brasília: Athalaia.

MACHADO, I. J. R. (2010) Reordenações da casa no contexto migratório de Governador Valadares, Brasil. Etnográfica, Lisboa, vol. 14, p. 5-26.

Martes, A. C. B. (1999). Brasileiros nos Estados Unidos: um estudo sobre imigrantes em Massachusetts. São Paulo: Paz e Terra.

Morais, S. S. (2009). Caminhos entre continentes: estudantes dos Palop em universidades brasileiras e suas dinâmicas identitárias. Trabalho de Conclusão do Curso (Ciências Sociais/Bacharelado com Habilitação em Antropologia) Departamento de Antropologia - Instituto de Ciências Sociais, Universidade de Brasília, Brasília.

MungoI, D. (2006). O Mito Atlântico: relatando experiências singulares de mobilidade dos estudantes africanos em Porto Alegre no jogo de construção e reconstrução de suas identidades étnicas. Dissertação (Mestrado em Antropologia Social) - Instituto de Filosofia e Ciências Humanas, Universidade Federal do Rio Grande do Sul, Porto Alegre. 
SARGENT, C.; LARChANCE-KIM, S.; YATERA, S. (2007). "Migração e telecomunicações: tecnologias e famílias transnacionais na França e África Ocidental". Cadernos Pagu, Campinas, n. 29, p. 257-284. Disponível em: <http://www.scielo.br/scielo. php?script $=$ sci_arttext $\&$ pid $=S 0104-83332007000200011 \& \operatorname{lng}=$ pt $\& n r m=i s o>$. Acesso em 10 abr. 2011.

SubuhanA, C. (2009). "A experiência sociocultural de universitários da África lusófona no Brasil: entremeando histórias”. Revista Pró-Posições, Campinas, v. 20, n. 1 (58), p. 103-126. Disponível em: <http://mail.fae.unicamp.br/ proposicoes/textos/58dossie-subuhanac.pdf>. Acesso em: 15 Abr. 2011.

TuRner, V. (1974). O processo ritual - estrutura e antiestrutura. Petrópolis: Vozes.

Velho, G. (1994). Projeto e metamorfose - antropologia das sociedades complexas. Rio de Janeiro: Jorge Zahar.

Recebido em abril/2012

Aprovado em abril/2013 